\title{
Supervision of a Sample of Clinical and Counselling Psychologists in the UK: A Descriptive Study of their Practices, Processes and Perceived Benefits
}

\author{
Helen Nicholas ${ }^{1 *}$, Rodney Goodyear ${ }^{2}$
}

\begin{abstract}
Literature on practitioner psychologist supervision remains underdeveloped. This mixed-methods, descriptive and exploratory study provides information about the supervisory practices of 72 registered practitioner psychologists in the UK. The primary purpose of this study was to characterise the supervision that practicing clinical and counselling psychologists receive. In addition to addressing the frequency; process and practices of supervision within this population, the study looked at the between-specialty differences in the use of supervision and the impact that practitioners' self-ratings of clinical mastery had on supervision. Participants completed an online survey. The quantitative findings showed that supervision was held at regular intervals; had an individual rather than group supervision format; and relied heavily on self-reporting. The participants reported engaging in supervision almost three times per month and were in supervisory relationships spanning multiple years. Supervisors were often line managers assigned to the role, which raises multiple relationship issues. The qualitative data, thematically analysed, produced three themes which highlighted the benefits of (a) having a space for personal development, reflection and mentoring; (b) the direction and instruction that supervision had provided them; and (c) how they valued the relational elements of the supervision experience. The findings presents valuable descriptive information about the supervision experiences of practitioner psychologists, how supervisors are assigned, how much supervision experienced psychologists undertake, and the benefits these supervisees report deriving from supervision. Practitioner psychologists may reflect on how they receive/provide supervision and how they could tailor supervision to the needs of their supervisees and to their own competencies.
\end{abstract}

\section{Keywords}

counselling psychology, clinical psychology, practitioner psychologist, benefits of supervision, supervisory relationship

${ }^{1}$ HCN Psychology, Frome, Somerset, United Kingdom

${ }^{2}$ University of Redlands, Redlands, CA, USA

*Corresponding author: henpsychology@gmail.com

\section{Introduction}

Clinical supervision is essential to psychotherapists' professional development Falender and Shafranske (2004); Orlinsky and Rønnestad (2005) and to monitoring the quality of client care that supervisees provide (Goodyear, Falender, $\&$ Rousmaniere, 2017). Commensurate with its importance, a robust literature has emerged to inform our understanding of supervision processes (Bernard \& Goodyear, 2019) and impacts (see e.g., Allan, McLuckie, \& Hoffecker, 2017; Watkins Jr., 2020; Wheeler \& Richards, 2007), as well as expected supervisory best practices (American Psychological Association, 2014, 2015; Borders et al., 2014; Ellis et al., 2014). However, the focus of this literature has been primarily on the supervision of trainees, with only a very few studies focusing on the supervision of practicing psychologists.
This is significant because most psychologists do continue to receive supervision once they are qualified to practice. For example, in one study, (Lichtenberg, Goodyear, Overland, \& Hutman, 2014), more than half (55\%) of a national sample of U.S. counselling psychologists reported that they continue to participate in supervision, even though psychologists in the US are not required to receive supervision (unless as a disciplinary action by regulatory boards; Bernard \& Goodyear, 2019). Virtually all psychologists in Australia and New Zealand participate because their regulatory boards require it. As well, rates of participation in supervision are very high in the United Kingdom (UK) and Ireland (88\% in Ireland, per McMahon \& Errity, 2014) where professional and regulatory bodies do not explicity mandate that registered psychologists ' participate in supervision, but do assert that their participation in supervision is expected.

These data suggest that both regulatory boards and practicing psychologists themselves perceive that clinical supervision 
of practitioners can be important. To some extent, that supervision can be informed by what we know of the supervision of trainees, however, only to some extent, as practicing psychologists have different professional needs than trainees and they work with greater autonomy. A few studies have responded to this need to know more about the supervision of practitioners (Gabbay, Kiemle, \& Maguire, 1999; Grant \& Schofield, 2007; McMahon \& Errity, 2014; Townend, Iannetta, \& Freeston, 2002), providing initial results that are begining to create an evolving portrait of that supervision.

The intent in this study was to sharpen the details of that portrait. The sample included practitioner psychologists in the UK, a group who are strongly encouraged, but not mandated to participate in supervision. In line with prior studies, to which the current study intends to add, this was primarily descriptive research.

\section{Sharpening the Evolving Portrait of Practitioner Su- pervison}

Pursuing the research goal of sharpening the emerging portrait of practitioner supervision meant employing the prior studies as a foundation. Along with earlier researchers (Gabbay et al., 1999; Grant \& Schofield, 2007; Lichtenberg et al., 2014; McMahon \& Errity, 2014; Townend et al., 2002), we were interested in how respondents chose or were assigned to their supervisors, how often they participated in supervision, the durations of their supervisory relationships, what occurred in their supervision (including format and modality), and what value and effects they perceived that supervision to have had. In addition, we were interested in how respondents * levels of self-confidence and psychology specialty affected their participation.

How supervisees are partnered with their supervisors has implications for both what they might learn, and the quality of their relationships with their supervisor. Whereas trainees are usually either assigned to supervisors or provided a restricted range of choices, practitioners, more typically, are able to choose their supervisors. However, this is not always the case. Townend et al. (2002), noted the frequency with which practitioners were assigned to a line supervisor, and discussed their concerns about the multiple relationships that result. They also noted that when practitioners choose their supervisors with whom they have existing relationships, they can set up multiple relationships. In their study of UK CBT therapists, $17 \%$ of the practitioner supervisees in their sample were supervised by their line managers and that $42 \%$ worked with a supervisor with whom they had an existing personal relationship of some kind, including "friend, friend's partner and on one occasion... the therapist's partner" (p. 494). Therefore, our first research question was: How were respondents matched with their supervisors?

We also were interested in how frequently practitioners participate in supervision. Ellis and his colleagues (Ellis et al., 2014; Ellis, Creaner, Hutman, \& Timulak, 2015) have argued that for supervision of trainees to qualify as minimally adequate, it should occur at least weekly. Practitioners, reasonably, would meet less often as they have less pressing professional development needs, have developed the metacompetence (Falender Shafranske, in press) to know when to seek consultation, and their supervisors typically do not have the need to closely monitor their work to ensure client wellbeing. In fact, only a little more than a quarter of those in the Lichtenberg et al. (2014) sample, who reported voluntarily participating in supervision, did so weekly, though $61 \%$ did so at least monthly. Roughly a third of Gabbay et al.'s (1999) respondents reported that they received weekly supervision and slightly more than a half reported being supervised at least biweekly. This was supported by McMahon and Errity (2014), where half $(51 \%)$ of their sample participated in supervision at least biweekly; $82 \%$ participated at least monthly.Townend et al. (2002) used a different metric in their study: the ratio of supervision hours to face-to-face work with clients, which they show to be 1 to 26 in their sample of British CBT therapists. This study was designed to add to this small knowledge base by using both metrics: frequency of meetings and ratio of supervision time to time engaged in professional practice. The research question being examined was: How frequently did respondents report participating in supervision?

Another consideration was the duration of the supervisory relationship. Trainees are unlikely to stay with a particular supervisor for more than a year, and typically less than that, as assigments usually are constrained by the training calendar. Practitioners do not have the kinds of bounded training experiences that trainees have and so are free to work with their supervisors for as long as it is useful to them. Although we were unable to find any studies that examined the length of practitioners' supervisory relationships, this seemed important to know duration of the supervisory relationship has bearing on the quality of the supervisory relationship and, potentially, on what supervisees learn. To address this, our research question was: What was the typical length of respondents' supervision with their current supervisors?

It is also useful to note the formats (e.g., individual, group, and so on) being used in supervision. Supervision is most frequently offered in an indivudal format as a dyadic experience (Borders et al., 2014). The existing studies of practitioner supervision (Gabbay et al., 1999; Grant \& Schofield, 2007; McMahon \& Errity, 2014; Townend et al., 2002) confirm that this is the case there as well. Although we expected to have similar findings, the question is sufficiently important to include in the current study and was: To what extent did respondents report that their supervision occurred in an individual versus a group format?

The modality in which supervision is offered is also important. Supervisee self-report is the modality that is most frequently used (Nelson, 2014), despite the substantial training and risk management advantages afforded by the use of direct observations, live supervision or video recordings (Haggerty \& Hilsenroth, 2011), of supervisees' clinical work. This also seems to be true for the supervision of practitioners as 
in Townend et al. (2002), where only $5 \%$ of their sample of CBT practitioners reported that audio or video recordings of their sessions were used "often;" and 13\% reported they were used "sometimes." Only $6 \%$ reported using live observation at least "sometimes." The research question addressing modality of supervision was: To what extent did respondents report that their supervisors employed self-report, audio recordings, video recordings, live supervision with one-way glass, and live supervision with video feed?

So far, studies of practitioner supervision have focused on the impacts of supervision primarily in terms of supervisee satisfaction (Tromski-Klingshirn \& Davis, 2007). Although that is important, this study focused more on the extent to which respondents perceived that their work had improved as a result. In addition, the study sought to investigate the benefits that respondents believed that they experienced as a result of their supervision. The research question in this case was: What outcomes and benefits did respondents report having derived from supervision?

Finally, findings reported in two earlier studies of the supervision of practitioner psychologists prompted questions that warranted follow-up. In particular, we were interested in whether self-estimates of clinical competence affected participation in supervision. Specifically, we hypothesized that the participants " ratings of their clinical mastery would be negatively associated with number of hours of supervision per month. That question was prompted by Grant and Schofield (2007) report that respondents who were not participating in supervision explained that "I do not feel I need supervision" and "I am very experienced and consult with peers when needed" (p. 6). This was examined by asking the research question: Would respondents' self-rated clinical mastery predict the frequency with which they participated in supervision?

The other question we examined concerned McMahon and Errity's (2014) finding counselling psychologists used supervision more frequently than their clinical psychology counterparts prompted us to include a similar question in this study. Specifically, we asked: Would clinical and counselling psychologists report differences in the frequency in which they participated in supervision?

In summary, the purpose of this descriptive study of British clinical and counselling psychologists was to extend the small literature on the supervision in which practitioner psychologists participate. Our goal of the questions for which we obtained quantitative responses was to gain descriptive information about the supervisory experiences of practitioner psychologists through survey questions. The aim of the openended question we asked about benefits respondents perceived themselves to have obtained from the supervision they were receiving was to allow for a more expansive understanding of their perceptions than would have been possible in a strictly quantitative approach. Therefore, the use of mixed methods was to generate descriptive and exploratory details about the supervisory relationship, process and practices of practitioner psychologists.

In the metaphor suggested earlier, the research intention was to provide additional detail and clarity to the portrait of practitioner supervision that is beginning to emerge from the few existing studies (Gabbay et al., 1999; Grant \& Schofield, 2007; McMahon \& Errity, 2014; Townend et al., 2002). The questions we asked were informed by the questions and findings of those studies.

\section{Method}

\section{Recruitment Procedures}

The inclusion criteria were that participants were registered practitioner psychologists, in clinical practice, and who were participating in supervision as supervisees. Participants were recruited through the social media feeds of the chair of the BPS Division of clinical psychology and the chair of the BPS Division of counselling psychology (DCoP). A further advert was placed in the DCoP fortnightly e-letter that goes out to DCoP members who have signed up to receive the e-letter. Personalised emails were sent to the clinical and counselling psychology doctoral training courses with the request that they forward it to "colleagues, former students, and other registered psychologists."

In 2019, the BPS had 20,243 chartered members (British Psychological Society, 2019), representing ten divisions of the society. The 72 responses were from two of these divisions, namely the Division of clinical psychology and the Division of counselling psychology. As the recruitment process was through the social media feeds of the divisional chairs at the time (a one-year term), it represented a small portion of the total divisional membership. Not all members of these two divisions would have been following the divisional chairs nor signed up to receive the DCoP e-letter. Included in the information was that participants would be eligible for a prize draw for a $£ 50$ Amazon gift certificate. The study was approved by the Institutional Review Board of the University of Redlands.

\section{Participants}

The sample comprised of 72 (84\% female; $14 \%$ male; $2 \%$ who did not report gender) British registered psychologists with a mean age of 44.25 years $(S D=12.03)$. Sixty-two reported that they were currently providing psychotherapy. They had a mean of 14.44 years $(S D=8.79)$ of clinical experience, and most reported that their highest degree was in clinical $(N=47)$ or counselling $(N=19)$ psychology; 5 reported "other" and 1 did not specify. Their highest degrees were DPsych $(N=39)$, PsychD $(N=9)$, Ph.D./D.Phil $(N=4)$, MSc/MRes/MPhil $(N=8)$ or "other" $(N=4)$. Their primary work settings were hospitals $(N=24)$, agencies or clinics $(N$ $=10)$, private practice $(N=5)$, college or universities $(N=4)$ or "other" $(N=25)$. Thirteen $(19.1 \%)$ reported that they were themselves providing supervision.

When given the option of one of five broad theoretical orientations from which to choose, most indicated they were eclectic or integrative $(N=37)$. The others were cognitive 
behavioural $(N=18)$, interpersonal $(N=7)$, psychoanalytic or psychodynamic $(N=3)$, or humanistic $(N=2)$; 1 did not respond to this question.

\section{Measures \\ Participants' Supervisors}

The survey asked participants questions about themselves, the person whom they regarded as their primary supervisor, and their supervision experiences. The items were developed collaboratively and included questions about participants' demographic characteristics (gender, age, highest degree); their professional training and qualification; clinical practice experience and therapeutic framework(s); self-perceptions of their own competence; goals for supervision; their perceptions of their supervision's impact on them and their clinical practice; and the modalities used in supervision. Participants were instructed that if they had more than one supervisor, they were to respond to the questions with reference to "the person whom you regard to be your primary supervisor".

Two scales were employed in the survey. One was the clinical subscale of Tsong and Goodyear's (2014) SupervisionOutcome-Scale. The other was a scale to assess supervisee's self-ratings of their clinical mastery that was developed for this study.

\section{Clinical Competence Subscale of the Supervision Out- come Scale (SOS)}

The 4-item Clinical Competence subscale of Tsong and Goodyear's (2014) Supervision Outcome Scale (SOS) was used to assess supervision impacts. Participants were asked to "Please rate the extent to which your supervisor has been helpful to you with respect to..." (1) improved treatment outcomes; (2) quality of relationships with clients; (3) skills; and (4) sophistication of case conceptualisations. Scaling ranged from $1=$ not at all helpful to $5=$ very helpful. It is important to note that because the first item originally asked about "decreasing client symptoms," which is only one measure of impact, we substituted the more inclusive language of treatment outcomes. The score was the mean score for the four items, with a possible range of $1-5$. Cronbach's alpha for this scale was .86 in the original scale development study (Tsong \& Goodyear, 2014) and .93 in this study, which marked a slight improvement in internal consistency.

\section{Supervisees' Clinical Mastery Self-Rating}

This scale was developed for this study to test the question concerning whether higher self-ratings of competence would be inversely related to the level of participation in supervision. In developing it, we were mindful of Bandura's 2006 advice to develop items that represent that efficacy or mastery construct as it is anchored within the particular domain of interest. The four items we developed asked about the extent to which participants believed they: (1) had mastered techniques and strategies involved in practicing therapy; (2) had mastered understanding what happens moment-by-moment during therapy sessions; (3) had developed precision, subtlety, and finesse in therapeutic work; and (4) felt capable to guide the development of other psychotherapists. Each item was rated on a 5 -point scale where $1=$ not at all and $5=$ very. The score was the mean score for the four items, with a possible range of $1-5$. The alpha coefficient for this scale was 87 .

\section{An Open-Ended Question About the Perceived Benefits of Supervision}

Participants were asked an open-ended question to identify what they perceived to be the most important benefit of their supervision. Specifically, they were asked: "What do you believe to be the single most important benefit you have received from this supervision?" Responses to the open-ended question were analysed using thematic analysis, chosen for its flexibility (King, 2004) and in order to identify, analyse and report common themes within the data.

The process of analysis broadly followed that outlined by Braun and Clarke (2006). Specifically, the process entailed familiarisation with the data, generating initial codes, searching for themes, reviewing preliminary themes, and defining and naming final themes, before ensuring that the final themes allowed for a coherent account of the participants' experience. The author's active role in identifying, selecting and reporting these themes is acknowledged as inevitable in the qualitative analysis of the data. We include direct quotes to add clarity to the identified theme and to demonstrate that the themes are rooted in the data (Whittemore, Chase, \& Mandle, 2001; Yardley, 2000).

\section{Results}

The results are organized by research question. Each is addressed in turn.

\section{How were respondents matched with their supervisors?}

Almost half $(N=35,48.6 \%)$ of the participants reported that they had chosen their own supervisors. The remaining 37 reported that their supervisor was assigned to them in their work setting. Responses to an open-ended question about choices reflected these findings, with one subset reporting that they had no choice (e.g. "manager at work"; was "decided for me"; "this was decided by the service"; "it was decided-she is the next band up") and others reporting having exercised choice (e.g. "I worked with him as a trainee and liked his style"; "I lost my existing supervisor, and looked around for a suitable substitute. I was very lucky to find this one"; "I chose a person I knew and felt I could work with").

To examine whether those who chose their own supervisors would rate the outcomes of supervision differently than those who were assigned their supervisors, we conducted a one-way analysis of variance (ANOVA) with using the SOS Clinical Competence Subscale as the dependent variable. There was no statistically significant between-group difference in how effective they rated their supervision $(F(1$, $68)=2.23, p=.14)$.

Nineteen (26.4\%) reported that their supervisor also was their line manager and four (5.5\%) reported having an outside 
friendship with the supervisor. Therefore, approximately a third were involved in a supervisory relationship that was a multiple relationship of some form by virtue of who their supervisor was. In addition, nine participants reported directly paying their supervisor for services (amounts ranged from $£ 44$ to $£ 100 ; M=£ 68$ ) which created an additional form of multiple relationship.

\section{How frequently did respondents report participating in supervision?}

These results address the questions about supervision involvements and processes that were raised earlier in this article, and are presented in that same order. The first of those concerned the frequency or amount of supervision. Participants reported that they received an average of 2.62 hours ( $S D$ $=1.52$ ) of supervision during a typical month across the past year from their primary supervisor. Using the metric Townend et al. (2002) had employed, this amounted to an average of one hour of supervision for every 34.34 hours of direct service that they reported having provided. Almost all $(N=$ $65 ; 90.3 \%)$ reported that supervision was regularly scheduled versus the $6(8.3 \%)$ who scheduled it on an as-needed basis (one person did not respond to this question).

\section{What was the typical length of respondents' supervision with their current supervisors?}

Participants varied considerably in the lengths of time they reported having worked with their current supervisor, ranging from just two months to over 13 years. The mean was 4.20 years $(S D=3.41)$.

To what extent did respondents report that their supervision occurred in an individual versus a group format?

Participants were asked to rate the extent to which their supervision was conducted in individual and in group formats, using for each question a scale that was anchored on one end $1=$ not at all, and on the other end $5=$ exclusively. The means were $4.46(S D=1.09)$ and $2.31(S D=1.49)$, respectively. Fifty-one (70.8\%) reported that their supervision was exclusively individual whereas $4(5.5 \%)$ reported that it was exclusively in a group format.

To what extent did respondents report that their supervisors employed self-report, audio recordings, video recordings, live supervision with one-way glass, and live supervision with video feed?

Participants were asked to report the extent to which their supervisors were employing each of five modalities in their sessions, using for each question a five-point scale anchored on one end $1=$ with never , and on the other end $5=$ in all sessions. Arranged in decreasing order of frequency, those ratings were: supervisee self-report $(M=4.50 ; \mathrm{SD}=1.14)$, audio recordings $(M=1.44 ; S D=.97)$, video recordings $(M$ $=1.25 ; S D=.88)$, live supervision using one way glass $(M=$ $1.18 ; S D=.76)$, live supervision using a video feed $(M=1.12$; $S D=.69)$. Fifty-eight $(80.5 \%)$ reported that their supervision was based exclusively on self-report.

\section{What outcomes and benefits did respondents report hav- ing derived from supervision?}

Participants' mean score on the SOS clinical competence scale was $4.02(S D=9.1)$, where the possible high score was 5. In addition we had asked respondents to report in an open ended question what they perceived to have been the single most important benefit they received from this supervision. Three themes were identified: (1) space for personal development, reflection and mentoring; (2) direction and instruction; and (3) relational element.

With respect to theme 1 (space for personal development, reflection and mentoring): Participants valued the support their supervisors provided while offering dedicated time and space for guided reflection. They appreciated the ability to engage in open discussion of both personal and professional issues, and each shared different experiences. It was noted that having a non-judgemental context outside the constraints of their work organisation helped participants build confidence. Participants also stated that their supervisor played an important role in their own professional development when it came to their clinical work. This holistic approach was important for participants, as was illustrated by one participant who stated that their supervisor:

... supports me as a whole person. Although our focus is the work, he has supported me through personal life crises in order to contain the effects around clients.

With respect to theme 2 (direction and instruction): Some supervisees reported their appreciation for the expertise their supervisors brings and imparts to them. This was highlighted the skills and expertise their supervisor had which was very relevant to the specific client group they were working with at the time (e.g., the respondent who expressed appreciation for the direction and instruction the supervisor brought with respect to "client groups particularly in terms of therapy and cognitive assessment"). This was further illustrated by a participant who wrote about how they appreciated their supervisor's "up to date knowledge of evidence base and interventions."

With respect to theme 3 (relational elements): This theme captured the value respondents placed on the relational elements of the supervision experience. Participants seemed to gain benefit from the supervisory relationship; appreciating the support, containment of their own feelings and normalising of their concerns discussed in supervision. This was illustrated in one participant writing about a particular situation where they had needed the support of their supervision and had appreciated that their supervisor had the "ability to recognise when I am overwhelmed." Another respondent mentioned the importance of having "someone to bear witness to the challenges and to help support resilience and a constructive approach when overwhelmed by multiple/contradictory demands.“ 
Would respondents' self-rated clinical mastery predict the frequency with which they participated in supervision?

There was no statistically significant relationship between participants" self-ratings of clinical mastery and the number of hours per month that they reported participating in supervision (Pearson $r=.12 ; p<.371$ ).

\section{Would clinical and counselling psychologists report dif- ferences in the frequency in which they participated in supervision?}

The one-way analysis of variance showed that counselling psychologists participated in supervision significantly more frequently than clinical psychologists, with mean reported sessions per month of $3.24(S D=1.55)$ and $2.31(S D=1.26)$ respectively; $F(1,63)=6.47, p=.013)$. The resulting Cohen's $d$ of .69 suggests a medium to large effect size. To examine this between-specialty difference using a different metric: whereas counselling psychologists reported receiving one hour of supervision for every 32.0 hours of direct service, clinical psychologists reported receiving one hour of supervision for every 41.1 hours of direct service.

Reasoning that perhaps these findings could be explained by counselling psychologists having lower level of self-rated clinical competence (and therefore having higher levels of perceived need for supervision), we conducted an additional one-way ANOVA with clinical competence as the dependent variable. Because counselling psychologists rated their competence as higher than the clinical psychologists $(F(1,57)=$ $8.35, p=.005)$, the between-specialty differences in amount of supervision received is likely not accounted for by participant's perceptions of their competence levels.

\section{Discussion}

The findings of the current study add to the small body of literature describing the supervision of practitioner psychologists. In so doing, the study provides additional clarity to the portrait that is emerging of those supervision practices. For example, this and previous studies (which are summarized in Table 1) make clear that although the supervision of practitioners occurs somewhat less regularly than the once per week minimum Ellis et al. (2014) suggested for trainees, it is still frequent. The nearly 3 hours per month that the typical respondent reported participating in supervision represents an appreciable investment of time and commitment for psychologists in practice (and often for their employers as well). In fact studies have been consistent in indicating that the majority of practitioner psychologists who receive supervision are doing so at least once every two weeks. This seems appropriate for supervisees at their levels of development and with their supervisory needs.

Slightly more than half reported that their supervisor was assigned to them and a substantial subset were supervised by their line managers. That these supervisors were assigned may suggest that their work setting required them to be supervised, even if this was not required as a condition of regulation / registration. But to be supervised by line managers raises multiple relationship issues even though this and other studies (McMahon \& Errity, 2014; Townend et al., 2002) suggest that this is a prevalent practice. Although this can provide benefits for the supervisee (Boswell, Stark, Wilson, \& Onwuegbuzie, 2017) it can also pose ethical issues (Tromski-Klingshirn \& Davis, 2007). For example, if in the course of clinical supervision, a psychologist were to reveal an egregious error that had put a client in danger, how is the supervisor - now functioning in the role of line manager - to respond? Whereas someone whose role is solely that of a clinical supervisor might regard it as a learning error to be corrected, a line manager might be forced to document it as an instance of unsatisfactory performance that required a sanction of some sort.

Supervisees in this sample tended to have multi-year relationships with their supervisors. This extended supervisory relationship can allow for more extended and perhaps deeper reflection and reflexivity as well as the opportunity to supervise work over an extended period. It may also be useful in discussing workload, individual cases in more depth and to follow the process of therapy and development that the supervisee engages in. This longer-term relationship would allow the supervisor to highlight any continuing professional development and training needs of the supervisee in a collaborative and safe environment. A line manager as supervisor may also be able to ensure that the organisations' policies and procedures are being adhered to. Some drawbacks to having a long-term supervisory relationship may include both losing objectivity in reviewing supervisees' work, and boundary crossing and violations. For example, the supervisee may become complacent in what they tell their supervisor and issues around disclosure may arise. When the boundaries between supervisor and friendship become blurred, this may raise ethical considerations. The balance between a professional or collegial relationship and that of more of a friendship therefore needs to be monitored within the supervisory relationship.

That individual supervision is used heavily is a consistent finding across all studies of practitioner supervision (Gabbay et al., 1999; Grant \& Schofield, 2007; McMahon \& Errity, 2014; Townend et al., 2002), including this. An individual format may lend itself better to discussing individual clients in depth, in comparison to group supervision, where supervisees may take it in turn to present a case from their workload. Live observation was also used to a much greater extent than video review, possibly due to the lack of facilities available. Many psychology training universities have the facilities to video record session, however in the UK National Health Service, this is far less common and it is also not standard practice in private practice. Direct observation is now considered a supervision best practice (American Psychological Association, 2014, 2015; Roth \& Pilling, 2008) for trainees and we believe this should be the case for practitioner psychologists as well.

Whilst frameworks such as PURE (prepare, undertake, refine, and enhance; Lane \& Corrie, 2016) outline the core 
function and tasks of effective supervision, these speak to the skill and competence-development focus of supervision. However, one theme in participants ' responses to the openended question about benefits of supervision concerned an additional advantage of supervision: that of providing support and a space for personal development and reflection. McMahon (2014) suggested as guiding principles for the supervisory that the supervisor (1) offer emotional presence and sensitivity; (2) value both vulnerability and competence; (3) offer knowledge and experience with humility and (4) develop a relationship to support continued personal and professional growth. Although these attributes of supervision are no doubt valuable to all supervisees, these results suggest that the relational support and space for reflection may assume particular importance with supervisees who are practitioners (Sharrock, Javen, \& McDonald, 2013).

The finding that counselling psychologists used supervision more frequently than their clinical psychology counterparts replicates that of McMahon and Errity (2014). As respondents' clinical experience increased, their self-perception of becoming more clinically competent increased as well, which is consistent with findings obtained in other studies (e.g., Orlinsky \& Rønnestad, 2005). Levels of self-perceived competence did not predict the frequency with which participants participated in supervision. The finding that it predicted the extent to which their supervision relied on self-report, does however suggest that they may be less motivated to directly examine their actual performance in ways that other supervision modalities afford.

With one exception (Gabbay et al., 1999), the majority of respondents in prior studies have perceived their supervision as more adequate or satisfactory than not. For this study, we asked about perceived outcomes rather than satisfaction and found that respondents perceive that their supervision to be generally very effective.

\section{Limitations and Suggestions for Future Research}

The findings of this study are generally consistent with the studies summarized in Table 1 in cases in which similar questions were asked. Nevertheless, the low response rate was sufficiently low to warrant cautions in generalizing the results to the population of British psychologists. It is difficult to know, for example, whether those who chose to participate were different in some important way (e.g., level of interest in or commitment to supervision) than those who did not. This speaks to the importance of replication with a larger sample.

The scale measuring self-estimates of competence was developed for this study and so its validity has not been established. For that reason, these results should be considered tentative pending additional work to establish the scales psychometric properties.

Future research should focus on examining the extent to which those who receive supervision are doing so voluntarily versus as a work requirement. Although we could infer that this was true of many of those who reported being assigned a supervisor at work, there was no question in our survey that explicitly asked about whether they supervision the respondent was receiving was mandatory. Reasonably this is a variable that would affect not only choice of supervisor but how supervision is delivered and its focus and addressing it would help develop more differentiated understandings of practitioner supervision.

The finding that counselling psychologists used supervision more frequently than their clinical psychology counterparts replicated those of McMahon and Errity (2014). If that finding is replicated in still other studies, then it would be useful to have a better understanding of the reasons. It could be that counselling psychologists value supervision more than their clinical psychology counterparts. One indication of this was that 'The Division of counselling Psychology was the first within the British Psychological Society to insist on supervision for its members" (e.g. Woolfe \& Tholstrup, 2010, p. 591). Scott, Ingram, Vitanza, and Smith (2000) found that directors of counselling psychology doctoral programs valued supervision training more than their clinical psychology counterparts. But other factors may affect this between-specialty difference in supervision frequency and so should be investigated.

\section{Implications for Practice}

The study provides additional clarity to the portrait that is emerging around the supervisory practices of practitioner psychologists. It presents valuable descriptive information, albeit from a small sample, about the supervisor experiences of practitioner psychologists; how supervisors are assigned; how much supervision experienced psychologists undertake; and the benefits supervisees derive from supervision. Practitioner psychologists may reflect on how they receive / provide supervision and how they could tailor the process of supervision to the needs of their supervisees and to their own competencies.

\section{Summary and Conclusion}

As literature on practitioner psychologist supervision remains underdeveloped, it is important to gain information about the practices, processes and perceived benefits of supervision. This study addresses the frequency; process and practices of practitioner psychologist supervision as well as noting some key between-specialty differences in the use of supervision and the impact that practitioners' self-ratings of clinical mastery had on supervision.

\section{Funding}

This research received no external funding.

\section{Conflict of Interest}

The authors declare that they have no competing interests. 


\section{References}

Allan, R., McLuckie, A., \& Hoffecker, L. (2017). Protocol: Effects of clinical supervision of mental health professionals on supervisee knowledge, skills, attitudes and behaviour, and client outcomes: protocol for a systematic review. The Campbell Collaboration, 13(1), $1-44$.

American Psychological Association. (2014). Guidelines for clinical supervision for health service psychologists. Retrieved from https: / /www. apa.org/about/ policy/guidelines-supervision.pdf

American Psychological Association. (2015). Guidelines for clinical supervision in health service psychology. The American Psychologist, 70(1), 33-46.

Bandura, A. (2006). Guide for constructing self-efficacy scales. In T. Urdan \& F. Pajares (Eds.), Self-efficacy beliefs of adolescents (p. 307-337). Greenwich, CT: Information Age Publishing.

Bernard, J. M., \& Goodyear, R. K. (2019). Fundamentals of clinical supervision. New York: Pearson.

Borders, L. D., Glosoff, H. L., Welfare, L. E., Hays, D. G., DeKruyf, L., Fernando, D. M., \& Page, B. (2014). Best practices in clinical supervision: Evolution of a counseling specialty. The Clinical Supervisor, 33(1), 26-44. doi: 10.1080/07325223.2014.905225

Boswell, J., Stark, M. D., Wilson, A. D., \& Onwuegbuzie, A. J. (2017). The impact of dual roles in mentoring relationships: A mixed research study. The Journal of Counselor Preparation and Supervision, 9(2). doi: $10.7729 / 92.1175$

Braun, V., \& Clarke, V. (2006). Using thematic analysis in psychology. Qualitative Research in Psychology, 3(2), 77-101. doi: 10.1191/1478088706qp063oa

British Psychological Society. (2019). Review of the year 2019. Leicester: The British Psychological Society. Retrieved from https://www.bps.org.uk/ sites/www.bps.org.uk/files/Annual\% 20 Reports/Reviews/BPS20Review $200 f \%$ 20the 20 Year\%202019.pdf

Ellis, M. V., Berger, L., Hanus, A. E., Ayala, E. E., Swords, B. A., \& Siembor, M. (2014). Inadequate and harmful clinical supervision: Testing a revised framework and assessing occurrence. The Counseling Psychologist, 42(4), 434-472.

Ellis, M. V., Creaner, M., Hutman, H., \& Timulak, L. (2015). A comparative study of clinical supervision in the republic of ireland and the united states. Journal of Counseling Psychology, 62(4), 621-631. doi: 10.1037/ cou0000110

Falender, C. A., \& Shafranske, E. P. (2004). Clinical supervision: A competency-based approach (2nd ed.). Washington DC: American Psychological Association.

Gabbay, M., Kiemle, G., \& Maguire, C. (1999). Clinical supervision for clinical psychologists: Existing provision and unmet needs. Clinical Psychology \& Psychother- apy, 6(5), 404-412.

Goodyear, R. K., Falender, C. A., \& Rousmaniere, T. (2017). Ethics issues regarding supervision and consultation in private practice.

Grant, J., \& Schofield, M. (2007). Career-long supervision: Patterns and perspectives. Counselling and Psychotherapy Research, 7(1), 3-11. doi: 101080/ 14733140601140899

Haggerty, G., \& Hilsenroth, M. J. (2011). The use of video in psychotherapy supervision. British Journal of Psychotherapy, 27(2), 193-210. doi: 10.1111/ j.1752-0118.2011.01232.x

King, K. (2004). Using thematic templates in the thematic analysis of text. In C. Cassell \& G. Syman (Eds.), Essential guide to qualitative methods in organizational research (p. 256-270). London: SAGE.

Lane, M., D A Watts, \& Corrie, S. (2016). Supervision in the psychological professions: Building your own personalized model. London: Open University Press.

Lichtenberg, J., Goodyear, R., Overland, E., \& Hutman, H. (2014, March). A snapshot of counseling psychology: Stability and change in the roles, identities and functions (2001-2014). Paper Presented at the Counseling Psychology National Conference, Atlanta, GA.

McMahon, A. (2014). Four guiding principles for the supervisory relationship. Reflective Practice, 15(3), 333-346.

McMahon, A., \& Errity, D. (2014). From new vistas to life lines: Psychologists' satisfaction with supervision and confidence in supervising. Clinical Psychology \& Psychotherapy, 21(3), 264-275.

Nelson, M. L. (2014). Using the major formats of clinical supervision. In C. E. Watkins \& D. L. Milne (Eds.), The Wiley International Handbook of Clinical Supervision (p. 308-328). Oxford, England: John Wiley Sons.

Orlinsky, D. E., \& Rønnestad, M. H. (2005). How psychotherapists develop: A study of therapeutic work and professional growth. Washington, DC: American Psychological Association.

Roth, A. D., \& Pilling, S. (2008). A competence framework for the supervision of psychological therapies. Retrieved from http://www.ucl.ac.uk/pals/ research/cehp/research-groups/core/ competence-frameworks

Scott, K. J., Ingram, K. M., Vitanza, S. A., \& Smith, N. G. (2000). Training in supervision: A survey of current practices. The Counseling Psychologist, 28(3), 403422.

Sharrock, J., Javen, L., \& McDonald, S. (2013). Clinical supervision for transition to advanced practice. Perspectives in Psychiatric care, 49(2), 118-125.

Townend, M., Iannetta, L., \& Freeston, M. H. (2002). Clinical supervision in practice: A survey of UK cognitive behavioural psychotherapists accredited by the BABCP. Behavioural and Cognitive Psychotherapy, 30(4), 485.

Tromski-Klingshirn, D. M., \& Davis, T. E. (2007). Super- 
visees' perceptions of their clinical supervision: A study of the dual role of clinical and administrative supervisor. Counselor Education and Supervision, 46(4), 294-304. doi: 10.1002/j.1556-6978.2007.tb00033.x

Tsong, Y., \& Goodyear, R. K. (2014). Assessing supervision's clinical and multicultural impacts: The supervision outcome scale's psychometric properties. Training and Education in Professional Psychology, 8(3), 189-195.

Watkins Jr., C. E. (2020). What do clinical supervision research reviews tell us? surveying the last 25 years. Counselling and Psychotherapy Research, 20(2), 190208. doi: https://doi.org/10.1002/capr.12287

Wheeler, S., \& Richards, K. (2007). The impact of clinical supervision on counsellors and therapists, their practice and their clients. a systematic review of the literature. Counselling and Psychotherapy Research, 7(1), 54-65. doi: https://doi.org/10.1080/14733140601185274

Whittemore, R., Chase, S. K., \& Mandle, C. L. (2001). Validity in qualitative research. Qualitative Health Research, 11(4), 522-537.

Woolfe, R., \& Tholstrup, M. (2010). Supervision. In S. D. B. R.Woolfe R Strawbridge \& W. Dryden (Eds.), Handbook of counselling psychology (3rd ed., p. 590608). London: Sage.

Yardley, L. (2000). Dilemmas in qualitative health research. Psychology and Health, 15(2), 215-228. 


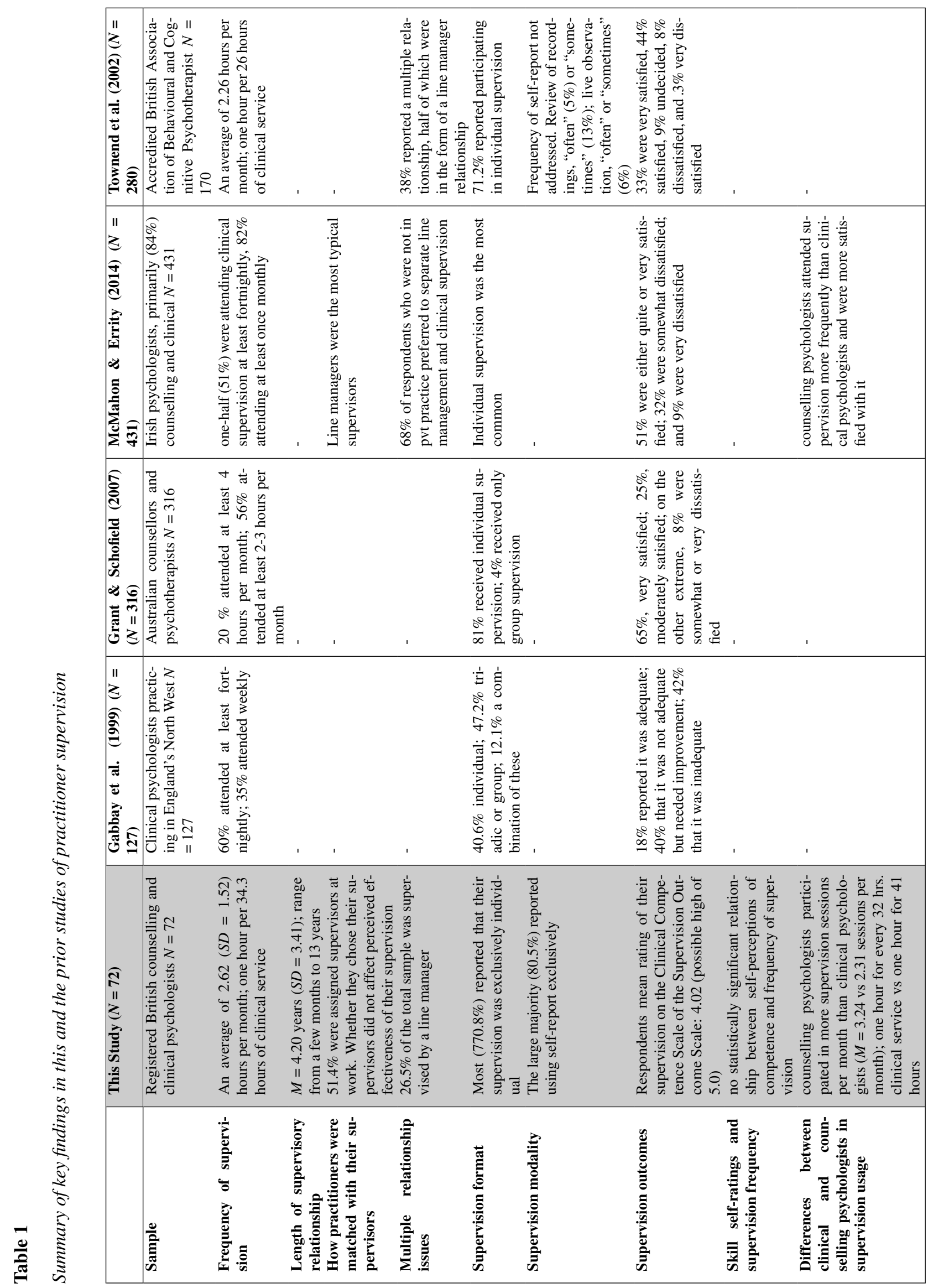

